\title{
Glycoprotein IIb/IIIa Inhibitors to Facilitate Percutaneous Intervention in ST-Elevation Myocardial Infarction
}

\author{
- The Sooner not Necessarily the Better - \\ Luis A Guzman, MD
}

$\mathbf{E}$ arly, complete and persistent reperfusion are the main therapeutic goals for patients presenting with STelevation myocardial infarction (STEMI). Percutaneous coronary intervention (PCI) is the preferred reperfusion therapy in this setting. ${ }^{1}$ Despite our best efforts, several hurdles exist to provide timely reperfusion with PCI for maximizing salvage of myocardium. Patient related delays, the lack of availability of cardiac catheterization laboratory in all hospitals, as well as the logistic limitations and cost of having around the clock coverage, conspire to increase the time delay from symptom onset to PCI. The need to transfer patient to facilities with PCI capabilities is also a well known limitation of this therapy., ${ }^{2,3}$ The ideal reperfusion strategy for STEMI patients with an expected delay to PCI is still not well established. Several approaches have been proposed to improve time to reperfusion and overcome these limitations. In particular, 2 main areas have been the object of focus. The first one relates to programs to speed patient transfer to a receiving PCI hospital. Different protocols of field recognition, ECG in the field and electronic data transferring, as well as more ambitious field activation of the cathether laboratory STEMI team, have successfully demonstrated improved time to reperfusion. ${ }^{4}$ Early pharmacologic reperfusion has been the second area of interest. Several studies have demonstrated significantly better outcomes when a Thrombolysis In Myocardial Infarction (TIMI) III flow at the time of the PCI is present in the infarct-related artery. ${ }^{5}$ Early, upstream pharmacologic treatment appears as an attractive alternative approach to limit the duration of ischemic time when the timing to primary PCI for definitive treatment cannot be achieved. This concept, defined as 'facilitated PCI', has been recently extensively explored. Two main families of pharmacologic agents were evaluated as potential candidates; thrombolytic agents and Glycoprotein IIb/IIIa inhibitors, used either solely or in combination. Several small randomized pilot studies to test the efficacy of this approach have shown very promising initial results with improved TIMI flow prior to PCI as well as tissue perfusion measured by blush grade and degree of ECG resolution. ${ }^{6}$ The clinical benefits of this approach were however challenged when more appropriate, larger multicenter clinical trial were performed. The ASSENT-4-PCI study (Assessment of the Safety and Efficacy of a New Treatment Strategy with Percutaneous Coronary
Intervention), which tested the role of full dose tenecteplase in a randomized fashion, terminated prematurely due to an increase rate of hemorrhagic and non-hemorrhagic stroke contributing to an increase of in-hospital mortality found with the facilitated PCI approach. ${ }^{7}$ The FINESSE trial (Facilitated Intervention with Enhanced Reperfusion Speed to Stop Events) more recently evaluated the same facilitated-PCI concept using 2 different upstream regimens: half dose retaplace+ Glycoprotein IIb/IIIa inhibitors or Glycoprotein IIb/IIIa inhibitors alone pre PCI vs primary PCI without pharmacologic pretreatment. The study also failed to demonstrate any benefit in clinical endpoints among either of the facilitated strategies as compared with direct PCI, with an increase in bleeding complications with the combined lytic and Glycoprotein IIb/IIIa inhibitor strategy. ${ }^{8}$

\section{Article p1617}

In this issue of the Journal, Dong et al performed a metaanalysis of all randomized trials using early upstream small molecule Glycoprotein IIb/IIIa inhibitors vs deferred use strategy in the setting of STEMI treated with primary PCI. A total of 10 randomized trials were found including approximately 2,700 patients randomized to either strategy. The study showed that early upstream Glycoprotein IIb/IIIa inhibitors treatment was associated with improved TIMI flow and tissue perfusion pre-PCI. However, this initial angiographic benefit was not associated with improvement in post-PCI angiographic results. Similar incidence of death and recurrent myocardial infarction was also found with both strategies. In addition, even though not statistically significant, there was a strong trend to increase major and minor bleeding complications in the early upstream strategy. ${ }^{9}$ The results of this meta-analysis are actually in concordance with the above mentioned FINESSE trial in which the group receiving upstream Glycoprotein IIb/IIIa inhibitors either alone or in combination with half dose retaplace, had similar clinical outcomes as compared with the primary PCI cohort. ${ }^{8}$ The concordance was also noted with several prior studies regarding TIMI flow pre-PCI, in which patients randomized to upstream Glycoprotein IIb/IIIa inhibitors had higher TIMI flow than the differed group and no difference were noted with the post-PCI results between both strategies. ${ }^{6}$

The opinions expressed in this article are not necessarily those of the editors or of the Japanese Circulation Society.

Received May 25, 2010; accepted May 26, 2010; released online July 14, 2010

Cardiac Catheterization Laboratory; The Cardiovascular Center, University of Florida, College of Medicine, Jacksonville, FL, USA

Mailing address: Luis A Guzman, MD, The Cardiovascular Center, University of Florida, College of Medicine, 655 West $8^{\text {th }}$ Street ACC/

$5^{\text {th }}$ Floor, Jacksonville, FL 32209, USA. E-mail: luis.Guzman@jax.ufl.edu

ISSN-1346-9843 doi:10.1253/circj.CJ-10-0509

All rights are reserved to the Japanese Circulation Society. For permissions, please e-mail: cj@j-circ.or.jp 
Intuitively, it is reasonable to believe that the association of 2 strategies that have proven benefits in the same patient population when used in combination (PCI and Glycoprotein $\mathrm{IIb} / \mathrm{III}$ inhibitors in STEMI patients), and the concept of early reperfusion by using the Glycoprotein IIb/IIIa inhibitors upfront, would theoretically benefit clinical outcomes. Why facilitated PCI with Glycoprotein IIb/IIIa inhibitors did not demonstrate clinical benefit? Several explanations can be hypothesized. First, the time gained by the early infusion of Glycoprotein IIb/IIIa inhibitors might not have been enough to improve the already delayed reperfusion time to PCI. It has been shown that after the initial $2 \mathrm{~h}$ from symptom onset, there is no significantly larger salvaged myocardium. ${ }^{10}$ Most of the patients included in this meta-analysis have median time to reperfusion therapy beyond these $2 \mathrm{~h}$ threshold from symptom onset. Second, even though there was a higher incidence of pre-intervention TIMI 3 flow and tissue perfusion in the upstream Glycoprotein IIb/IIIa inhibitor infusion strategy, this was achieved in only $23 \%$ of patients with an absolute difference between groups of only $6 \%$, difference that probably is not enough to demonstrate any clinical benefits between strategies. Third, the main indicators of improved outcomes are the post-PCI TIMI flow and degree of tissue perfusion, which in the current analysis were identical in both groups, supporting the lack of clinical benefits. ${ }^{11}$ Forth, the increase bleeding complication with the early approach might have masked any benefits related to the early improved TIMI flow. Bleeding complications during PCI have been associated with an increase risk of ischemic events, including mortality. Several reasons have been proposed to explain this association, including the pro-coagulant effect of transfused blood products, early discontinuation of antiplatelets agents, as well as the increase clinical risk characteristics of patients with bleeding problems. ${ }^{12}$

Irrespective of the results of the current analysis, there is a need to improve access to reperfusion therapy in a significant proportion of patients. Timing is very important and if benefit of an early pharmacologic approach is to be demonstrated, it will likely be in patients in which a large amount of myocardium is involved as well as those in which no significant irreversible damage has been already created. To this extent, the FINESSE trial provide some light at the end of the tunnel. Patients randomized with large infarcts (left ascending artery distributions), and higher risk patients (TIMI risk score $\geq 3$ ) had a better outcomes with upstream pharmacologic treatments. ${ }^{13,14}$ Patients with very early presentation, less than 2-3h in which delays to PCI are likely (eg, patients admitted to a non-PCI facility requiring hospital transferring), are probably another group of patients in which the facilitated pharmacologic approach might prove benefit. Retrospective analysis of both the FINESSE and the ASSENT IV trials consistently showed improved clinical outcomes in those treated with the facilitated approach when the time to presentation was less than $4 \mathrm{~h}$ and those with longer delay times. ${ }^{13-15}$ In the mean time, until more information is available, the current meta-analysis as well as results from recent randomized trials, clearly demonstrate that the facilitated upstream pharmacologic approach either with thrombolytics and/or Glycoprotein IIb/IIIa inhibitors is not indicated for routine use in patients with STEMI.

\section{References}

1. Canadian Cardiovascular Society; American Academy of Family Physicians; American College of Cardiology; American Heart Association, Antman EM, Hand M, Armstrong PW, Bates ER, Green LA, Halasyamani LK, et al. 2007 focused update of the ACC/AHA 2004 guidelines for the management of patients with ST-elevation myocardial infarction: A report of the American College of Cardiology/American Heart Association Task Force on Practice Guidelines. J Am Coll Cardiol 2008; 51: 210-247.

2. Nakayama N, Kimura K, Endo T, Fukui K, Himeno H, Iwasawa Y, et al. Current status of emergency care for ST-elevation myocardial infarction in an urban setting in Japan. Circ J 2009; 73: 484-489.

3. Kiernan TJ, Ting HH, Gersh BJ. Facilitated percutaneous coronary intervention: Current concepts, promises, and pitfalls. Eur Heart $J$ 2007; 28: 1545-1553.

4. Henry TD, Sharkey SW, Burke MN, Chavez IJ, Graham KJ, Henry $\mathrm{CR}$, et al. A regional system to provide timely access to percutaneous coronary intervention for ST-elevation myocardial infarction. Circulation 2007; 116: $721-728$.

5. Stone GW, Cox D, Garcia E, Brodie BR, Morice MC, Griffin J, et al. Normal flow (TIMI-3) before mechanical reperfusion therapy is an independent determinant of survival in acute myocardial infarction: Analysis from the primary angioplasty in myocardial infarction trials. Circulation 2001; 104: 636-641.

6. Montalescot G, Borentain M, Payot L, Collet JP, Thomas D. Early vs late administration of glycoprotein $\mathrm{IIb} / \mathrm{III}$ inhibitors in primary percutaneous coronary intervention of acute ST-segment elevation myocardial infarction: A meta-analysis. JAMA 2004; 292: $362-$ 366.

7. Assessment of the Safety and Efficacy of a New Treatment Strategy with Percutaneous Coronary Intervention (ASSENT-4 PCI) Investigators. Primary versus tenecteplase-facilitated percutaneous coronary intervention in patients with ST-segment elevation acute myocardial infarction (ASSENT-4 PCI): Randomised trial. Lancet 2006; 367: $569-578$.

8. Ellis SG, Tendera M, de Belder MA, van Boven AJ, Widimsky P, Janssens L, et al; FINESSE Investigators. Facilitated PCI in patients with ST-elevation myocardial infarction. $N$ Engl J Med 2008; 358: 2205-2217.

9. Dong L, Zhang F, Shu X. Upstream vs deferred administration of small-molecule glycoprotein IIIb/IIIa inhibitors in primary percutaneous coronary intervention for ST-segment elevation myocardial infarction: Insights from Randomized Clinical Trials. Circ J 2010; 74: $1617-1624$.

10. Stone GW, Gersh BJ. Facilitated angioplasty: Paradise lost. Lancet 2006; 367: 543-546.

11. Sorajja P, Gersh BJ, Costantini C, McLaughlin MG, Zimetbaum P, Cox DA, et al. Combined prognostic utility of ST-segment recovery and myocardial blush after primary percutaneous coronary intervention in acute myocardial infarction. Eur Heart J 2005; 26: 667-674.

12. Rao SV, Eikelboom JA, Granger CB, Harrington RA, Califf RM, Bassand JP. Bleeding and blood transfusion issues in patients with non-ST-segment elevation acute coronary syndromes. Eur Heart $J$ 2007; 28: 1193-1204.

13. Ellis SG, Tendera M, de Belder MA, van Boven AJ, Widimsky P, Andersen HR, et al; FINESSE Investigators. 1-year survival in a randomized trial of facilitated reperfusion: Results from the FINESSE (Facilitated Intervention with Enhanced Reperfusion Speed to Stop Events) trial. JACC Cardiovasc Interv 2009; 2: 909916.

14. Herrmann HC, Lu J, Brodie BR, Armstrong PW, Montalescot G, Betriu A, et al; FINESSE Investigators. Benefit of facilitated percutaneous coronary intervention in high-risk ST-segment elevation myocardial infarction patients presenting to nonpercutaneous coronary intervention hospitals. JACC Cardiovasc Interv 2009; 2: $917-$ 924.

15. Ross AM, Huber K, Zeymer U, Armstrong PW, Granger CB, Goldstein $\mathrm{P}$, et al. The impact of place of enrollment and delay to reperfusion on 90-day post-infarction mortality in the ASSENT-4 PCI trial: Assessment of the safety and efficacy of a new treatment strategy with percutaneous coronary intervention. JACC Cardiovasc Interv 2009; 2: 925-930. 